\title{
The effects of genotype, caste, and age on foraging performance in leaf-cutting ants
}

\author{
Natasha Constant ${ }^{\mathrm{a}}$, Lorenzo A. Santorellia ${ }^{\mathrm{a}}$, Juliane F. S. Lopes, ${ }^{\mathrm{b}}$ and William O. H. Hughes ${ }^{\mathrm{a}}$

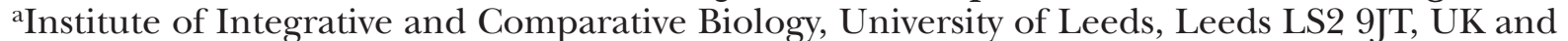 \\ bPós-Graduação Comportamento e Biologia Animal, Instituto de Ciências Biológicas/UFJF, Campus \\ Universitário de Martelos, Juiz de Fora 36.036-330, MG, Brazil
}

The evolution of polyandry is a general problem in behavioral ecology that has attracted particular interest in the social insects. Most social insects are monandrous (i.e., females are inseminated by a single male), but approximately a third of species have evolved polyandry (i.e., females are inseminated by multiple males), which can reach extreme levels. One of the leading explanations for polyandry is that genetically diverse colonies may have improved division of labor because of genotypic variation in the propensity of workers to engage in particular tasks. Here we investigate whether there may also be genotypic variation in the ability to carry out a task, by examining the effect of genotype, as well as caste and age, on the foraging performance of workers of the leaf-cutting ant Acromyrmex subterraneus. Larger ants cut larger fragments of orange-impregnated parafilm, and did so more quickly than smaller ants, whereas older ants also cut larger fragments but were slower to transport them. Most importantly, we found that patrilines within colonies differed significantly in the size of fragment cut, and the speed of cutting and transporting fragments when controlling for both ant size and fragment size in the analyses. Certain patrilines were better foragers, often in multiple ways, whereas other patrilines were significantly worse at foraging. Genotype can therefore affect the ability of social insect workers to carry out tasks as well as their previously shown propensity to engage in them, providing an additional mechanism by which genetic diversity may be beneficial to social insect colonies. Key words: division of labor, genetic diversity, genetic polyethism, polyandry, social insect. [Behav Ecol]

\section{INTRODUCTION}

$\mathrm{M}$ ultiple insemination of females by different males (polyandry) is common and taxonomically widespread, but is often hard to explain because it can carry significant costs to females, although clear benefits of the behavior are frequently elusive. Suggested benefits that may explain polyandry include direct benefits, such as sperm provision, nuptial gifts, and paternal care, and indirect genetic benefits, such as trading up, the dilution of genetic incompatibility, and increased offspring genetic diversity (Arnqvist and Nilsson 2000; Jennions and Petrie 2000; Simmons 2005). In contrast to most other animals, monandry (females inseminated by only a single male) is the most common and ancestral state in social insects, with females (queens) in only a third of species exhibiting some level of polyandry (Hughes et al. 2008a, 2008b). However, some of these are notable for having evolved exceptionally high or apparently obligate levels of polyandry. Explaining the evolution and maintenance of high polyandry in these social insects is particularly intriguing because direct benefits of the behavior are unlikely (Crozier and Fjerdingstad 2001). Attention has therefore focused on indirect genetic benefits that queens may obtain from polyandry, including the dilution of genetically incompatible matings and improved fitness of their offspring colony resulting

Address correspondence to W. Hughes. E-mail: w.o.h.hughes@ leeds.ac.uk.

N.C. Coauthor is now at the Department of Anthropology, Durham University, Durham DH1 3LE, UK.

L.A.S. Coauthor is now at the Department of Zoology, University of Oxford, Oxford OX1 3PS, UK.

Received 2 March 2012; revised 11 June 2012; accepted 19 June 2012.

(C) The Author 2012. Published by Oxford University Press on behalf of the International Society for Behavioral Ecology. All rights reserved.

For permissions, please e-mail: journals.permissions@oup.com from the increased genetic diversity of daughter workers that the queens produce.

One of the leading hypotheses for why increased offspring genetic diversity may improve the fitness of social insect colonies is via improved task performance (Crozier and Page 1985). Division of labor between individuals is the defining trait of social insects, and is affected by age, experience, body size, morphology, and physiology (Hölldobler and Wilson 1990; Robinson 1992, 2009; Ravary et al. 2007; Johnson 2010). If genotypes vary in their ability to carry out particular tasks, or their propensity to engage in them, then colonies with a greater diversity of genotypes may be better able to respond appropriately to changing environmental conditions (Oldroyd and Fewell 2007). In honeybees, for example, more genetically diverse colonies are better able to regulate the temperature of their colony and to exploit sudden increases in food supply (Jones et al. 2004; Mattila and Seeley 2007). The key assumption for this mechanism to work is the occurrence of genetic variation in task ability or propensity. There is now abundant evidence of genetic variation in task propensity in honeybees, with genotype influencing many behaviors including fanning, defensive behavior, undertaking, hygienic behavior, and foraging (Milne 1985; Robinson and Page 1988; Oldroyd et al. 1994; Arathi and Spivak 2001; Pankiw and Page 2001; Jones et al. 2004; Chapman et al. 2007). However, investigation of other social insects is far more limited. Task is largely determined by caste in some ants and several studies have found patriline variation in caste propensity in age-matched leaf-cutting ants, in which sperm use is essentially random (Hughes et al. 2003; Hughes and Boomsma 2007, 2008; Evison and Hughes 2011; Holman et al. 2011). Similar genetic effects on caste also appear to occur in army ants, harvester ants and Formica 
ants (Rheindt et al. 2005; Jaffé et al. 2007; Smith et al. 2008; Haapaniemi and Pamilo 2012). Recently, patriline variation in the propensity of workers of similar size and age to engage in foraging or waste management has also been found in leafcutting ants (Waddington et al. 2010).

In addition to influencing the propensity of workers to engage in particular tasks, it is also possible that genotype might affect the ability to carry out the task. Here we examine whether genotype influences the performance of foraging behavior in the leaf-cutting ant A. subterraneus. Leaf-cutting ants cut and transport pieces of leaves or other fresh vegetation back to their nests to form a substrate for an obligate mutualistic fungus, which they culture as their primary food source (Weber 1972). Colonies are generally headed by a single queen, and, in at least the 3 free-living Acromyrmex species examined previously (A. echinatior and A. octospinosus from Panama, and $A$. versicolor from the southern United States), these queens mate with multiple males (Reichardt and Wheeler 1996; Sumner et al. 2004; Nehring et al. 2011). Colonies thus consist of a number of genetic lineages (patrilines), which are the offspring of different fathers. As individuals from different patrilines share the same maternal genotype on average, maternal cues, and rearing conditions, they differ only in their paternal genotype and differences between patrilines thus represent genetic effects. We investigated whether the patriline, as well as the size and age, of leaf-cutting ants affect their foraging performance under controlled conditions.

\section{MATERIALS AND METHODS}

\section{Foraging experiments}

Experiments were carried out using 3 monogynous colonies of A. subterraneus subterraneus (As086, As087, As088) that were collected from Juiz de Fora, Minas Gerais, Brazil in October 2008. Colonies were set up in plastic boxes coated with Fluon (Whitford Plastics Ltd.) with the fungus garden inside an inverted plastic beaker. Colonies were maintained at $26{ }^{\circ} \mathrm{C}$, $85 \% \mathrm{RH}$, and $12 \mathrm{~h}: 12 \mathrm{~h}$ light:dark, on a diet of privet leaves and rice. During, and for at least $48 \mathrm{~h}$ before, the experiments, the colonies were starved of food to ensure the efficient recruitment of foragers and to prevent the emergence of differences in behavior due to satiation.

A foraging arena was set-up within each colony, linked by a 15-cm bridge to the beaker containing the fungus garden. Initially, a drop of $10 \%$ sucrose solution was presented within the foraging arena to encourage recruitment of foragers by scout ants. Once the first scout had discovered this and returned to the nest, the sucrose solution was removed along with any ants remaining in the foraging arena. A square of parafilm $(8 \mathrm{~cm} \times 8 \mathrm{~cm})$ impregnated in orange juice was then secured to the floor of the arena. Parafilm was used as a standardized material to avoid variation in natural leaves affecting foraging behavior and because parafilm impregnated with orange juice is attractive to Acromyrmex ants (Roces and Nunez 1993). Once ants arrived at the foraging arena, they cut semicircular fragments of the parafilm, which they then transported back to the fungus garden.

On the first day of each observational period, a number of measurements were taken and recorded for 25 ants from each colony: 1) the time taken to cut a parafilm fragment (seconds), 2) the speed of transporting the fragment along the bridge $(\mathrm{mm} / \mathrm{s})$, and 3$)$ the weight of the parafilm fragment cut and transported (mg). Individuals were collected with their loads at the end of the bridge and placed in separate plastic containers. The head width of each ant was then determined by taking a dorsal photograph with an Optika 5 camera and measuring the width between the eyes using the ImageJ software package. Individuals were then categorized into 4 physical size "castes" according to their head widths: $0.9-1.0 \mathrm{~mm}, 1.0-1.3 \mathrm{~mm}, 1.3-1.6 \mathrm{~mm}$, and $>1.6 \mathrm{~mm}$ (Camargo et al. 2006). The age of workers was estimated from their cuticle coloration as middle aged (medium brown) or old (dark brown) (Armitage and Boomsma 2010). The experiment was then repeated over 3 days, with data being collected for 25 ants per colony on each day. The first 50 ants in each colony that were middle-sized and middle-aged were stored in $100 \%$ ethanol at $-20{ }^{\circ} \mathrm{C}$ for later genotyping.

\section{Molecular analysis}

The 50 middle-sized and middle-aged workers from each of the 3 colonies were genotyped to determine their patriline. DNA was extracted from the legs of the ants using $5 \%$ Chelex resin (BioRad) and amplified at the microsatellite loci Ech4225 (Ortius-Lechner et al. 2000), Etta5 (Fjerdingstad et al. 1998), Atco13 and Atco15 (Helmkampf et al. 2008). Reactions were performed in $10 \mu \mathrm{L}$ volumes consisting of $1.5 \mu \mathrm{L}$ of DNA, $4 \mu \mathrm{L}$ of $1 \mathrm{mM}$ dNTP's, $2.4 \mu \mathrm{L}$ of $\mathrm{H}_{2} \mathrm{O}, 1 \mu \mathrm{L}$ of buffer, $1.2 \mu \mathrm{L}$ of $\mathrm{MgCl}_{2}, 1 \mu \mathrm{L}$ of primer, and $0.1 \mu \mathrm{L}$ of Taq polymerase. Amplification used a GeneAmp 9700 thermal cycler $(\mathrm{ABI})$ with a denaturing step of $94^{\circ} \mathrm{C}$ for $2 \mathrm{~min}, 30$ cycles of $94{ }^{\circ} \mathrm{C}$ for $30 \mathrm{~s}$, either $55^{\circ} \mathrm{C}$ (Ech 4225 and Atco15) or $65{ }^{\circ} \mathrm{C}$ (Atco13 and Etta5) for $45 \mathrm{~s}$, and $72^{\circ} \mathrm{C}$ for $2 \mathrm{~min}$, and finally $72{ }^{\circ} \mathrm{C}$ for $2 \mathrm{~min}$. PCR products were analyzed with an $3130 x l$ capillary sequencer (ABI) and allele sizes determined by comparison with internal size standards. The genotype of the mother queen and her multiple mates were deduced from the multilocus offspring genotypes. Workers were then assigned to patrilines according to their paternal alleles.

\section{Statistical analysis}

The 3 foraging variables (size of fragments cut, time taken to cut them, and transportation speed) were each analyzed using generalized linear models with a gamma distribution, log link function, and robust estimator of covariance, using the likelihood ratio chi square to test for significance of effects (Norusis 2011). The complete dataset was used to examine the effects of ant size category $(0.9-1,1-1.3,1.3-1.6$, or $>1.6 \mathrm{~mm}$ ) and age (middle-aged or old) on the dependent variables. Colony was included as a factor in the analyses, with the full model including the 2- and 3-way interactions between size, age, and colony. Fragment size was included as a covariate in the analyses of cutting and transporting times. In addition, the dataset of genotyped individuals was used to examine the effect of patriline on the 3 dependent foraging variables, with patriline nested within colony, ant size included as a covariate, and also fragment size included as a covariate in the analyses of cutting and transporting times. All analyses were carried out in IBM SPSS 19, with interaction terms removed from the full models in a stepwise manner to obtain the minimum adequate models.

\section{RESULTS}

With one exception noted below, all interaction terms were nonsignificant $(P>0.05)$ and therefore removed from the final minimum adequate models. There was a significant effect of the caste of an ant on the size of orange-impregnated parafilm fragment it cut $\left(\chi^{2}=83.9, \mathrm{df}=3, P<0.001\right)$, with larger ants cutting larger fragments and there being a reduced major axis regression slope of 1.82 in the $\log -\log$ relationship between ant size and square root-transformed fragment size (Figures 1a 
and Supplementary Figure S1). When controlling for fragment size, ant caste also affected the time taken to cut fragments, but not the speed of transporting them (respectively, $\chi^{2}=7.86, \mathrm{df}=3, P=0.049$; Figure $1 \mathrm{~b}$, and $\chi^{2}=1.92, \mathrm{df}=3$, $P=0.588$; Figure 1c). Larger ants were relatively quicker to cut their fragments, particularly so given that their fragments were larger. The age of an ant also significantly affected the size of fragment cut $\left(\chi^{2}=9.87, \mathrm{df}=1, P=0.002\right)$, and speed of transporting it $\left(\chi^{2}=9.47, \mathrm{df}=1, P=0.002\right)$. Older ants cut substantially larger fragments than middle-aged ants (Figure 1a), but took longer to transport them (Figure 1c). Older ants appeared to generally be quicker at cutting fragments than middle-aged ants, but the effect of age on this depended on the colony $\left(\chi^{2}=5.8, \mathrm{df}=2, P=0.016\right)$. Colonies also differed in the fragment sizes cut $\left(\chi^{2}=11.7, \mathrm{df}=2, P=0.003\right)$ and transportation speeds $\left(\chi^{2}=35.9\right.$, df $\left.=2, P<0.001\right)$, but there were no significant interactions between colony and the factors investigated $(P>0.05$ in all cases).

Most importantly, there were patriline differences in foraging performance. The 3 colonies As086, As087, and As088 contained respectively 4,9 , and 12 patrilines in total, with 3 , 6 , and 7 patrilines being sufficiently common to be included in the analysis. Patrilines nested within colonies differed significantly in the fragment sizes they cut when ant size was controlled in the analysis $\left(\chi^{2}=22.6, \mathrm{df}=13, P=0.047\right)$, and also both the time taken to cut fragments and speed of transporting them when ant and fragment size were controlled for (respectively, $\chi^{2}=92.3, \mathrm{df}=13, P<0.001$ and $\chi^{2}=33.8$, $\mathrm{df}=13, P=0.001)$. Ants from different patrilines within the same colony differed as much as approximately 2-fold in the size of fragment they cut, the time they took to cut it or the speed of transporting it (Figure 2). Notably, there was little evidence of the 3 foraging traits being traded-off. There was instead a tendency for patrilines, which were good at foraging in terms of cutting larger fragments, to also be good in terms of cutting them quickly (e.g., Patrilines 7A and 8A), whereas other patrilines appeared to be relatively poor foragers both in cutting smaller fragments and taking a long time to do so (e.g., Patrilines 6C, 8E, and 8F).

\section{DISCUSSION}

The results show that there is genotypic variation in the foraging performance of leaf-cutting ant workers. The level of genetic diversity found in the A. subterraneus colonies was similar to that reported in other free-living Acromyrmex species (Sumner et al. 2004; Nehring et al. 2011), with $8.3 \pm 2.3$ (mean \pm standard error $[\mathrm{SE}]$ ) patrilines per colony. In all 3 colonies examined, patrilines of similarly-sized and similarlyaged workers differed in the size of fragments they cut of orange-impregnated parafilm, the time they took to cut the fragments, and how quickly they transported the fragments back to their nest. The size of leaf-cutting ants affects their cutting ability (Wilson 1980), and genotype affects their size (Hughes et al. 2003; Hughes and Boomsma 2007), but this cannot explain the observed effects on foraging performance because all the ants genotyped were of similar size and size was also controlled for in the analyses. The result can also not be explained by patrilines differing in age because all the genotyped workers were of similar age based on their cuticular coloration and patriline representation does not change significantly over time in leaf-cutting ants (Hughes and Boomsma 2007; Holman et al. 2011). The patriline differences in foraging performance could, however, feasibly be because of experience or motivation. Patrilines in leaf-cutting ants and other social insects vary in their propensity to engage in foraging (Oldroyd and Fewell 2007; Waddington et al.
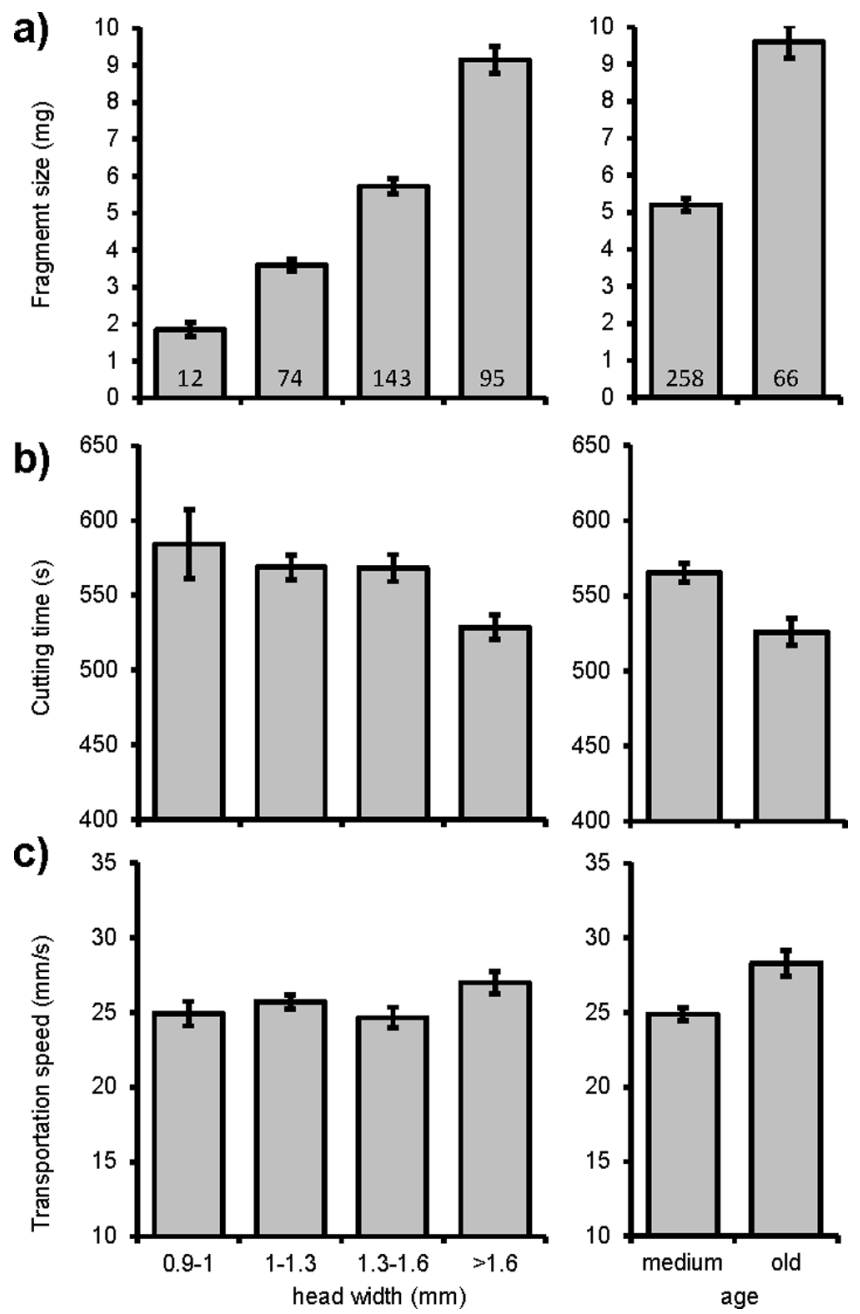

Figure 1

Mean \pm SE. (a) Size of orange-impregnated parafilm fragment cut, (b) time taken to cut fragment, and (c) speed of transporting the fragment back to the nest for leaf-cutting ant workers from the 4 size classes $(0.9-1.0 \mathrm{~mm}, 1.0-1.3 \mathrm{~mm}, 1.3-1.6 \mathrm{~mm}$, and $>1.6 \mathrm{~mm}$ head width) and 2 age classes (middle-aged or old, based on cuticular coloration). Sample sizes are given within the columns in the top graphs.

2010), so it is possible that individuals from some patrilines had been engaged in foraging for more of their life than individuals from other patrilines or may differ in motivation to forage. Both experience and motivation affects the foraging performance of social insect workers (O'Donnell and Jeanne 1992; Peat and Goulson 2005; Schippers et al. 2006; Ravary et al. 2007), and if there is patriline variation in experience or motivation then that could explain the results. Alternatively, it may be that patrilines vary in their neurological or morphological capabilities to forage, for example by varying in their mandibular strength, running ability, or their ability to assess optimum fragment size. Most probably, a combination of these mechanisms is responsible. These results focus specifically on the single task of foraging and it is important to remember that performance in one trait is likely to be traded-off against other traits. For example, leaf-cutting ants vary genotypically in disease resistance and the size of their energetically costly, antibiotic-producing metapleural glands (Hughes and Boomsma 2004; Hughes et al. 2010). Genotypes optimized for one task may not be as effective at other tasks, 
a)
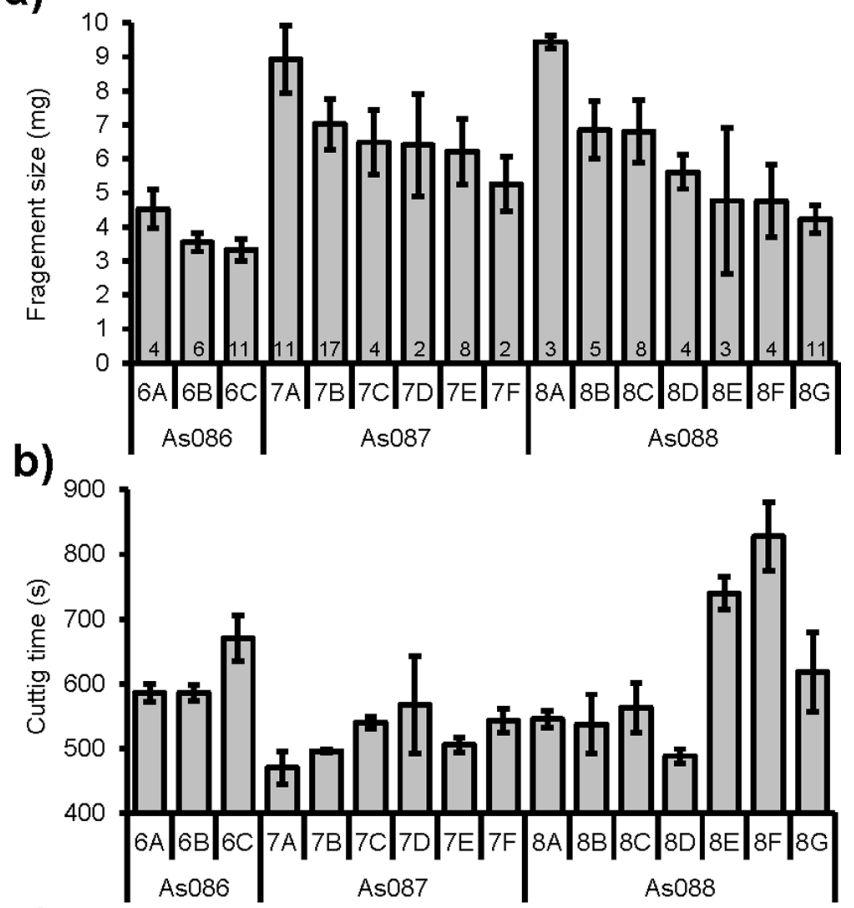

c)

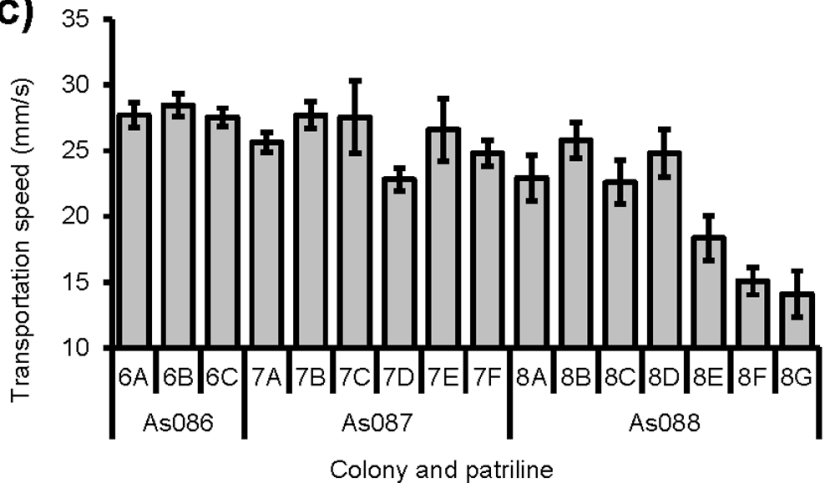

Figure 2

Mean \pm SE. (a) Size of orange-impregnated parafilm fragment cut, (b) time taken to cut fragment, and (c) speed of transporting the fragment back to the nest for middle-aged, middle-sized workers from different patrilines in each of 3 colonies of leaf-cutting ant (As086, As087, and As088). Sample sizes are given within the columns in the top graphs.

and colonies will therefore do best when they contain a diversity of genotypes such that there can be a division of labor between genotypes, just as there is between workers of different size, age, or experience.

Body size has been shown to affect the amount of material foraged in a diversity of social insects, including Atta leafcutting ants (Rudolph and Loudon 1986; Willott et al. 2000; Goulson et al. 2002; Roschard and Roces 2003). We found this to also be the case here, with larger ants cutting larger fragments. In leaf-cutting ants, ant size not only affects the mass of food which can be transported, but also determines the dimensions of leaf fragment cut and the energetic efficiency of cutting it (Wilson 1980). The greater performance of larger ants as foragers is illustrated by the steeper than isometric slope we found in the log-log relationship between fragment size and ant size, and the fact that larger ants cut their fragments more quickly. Accordingly, larger ants tend to become foragers rather than waste management workers (Waddington and Hughes 2010), with the size which engages in foraging being that which cuts leaves most efficiently (Wilson 1980). We also found that age affected foraging performance, with older ants cutting larger fragments and possibly cutting them somewhat quicker. This most likely reflects the benefit of experience (O'Donnell and Jeanne 1992; Peat and Goulson 2005; Schippers et al. 2006; Ravary et al. 2007), which apparently outweighed in this experiment any negative effect of mandible wear with age (Schofield et al. 2011). However, the benefit of experience in terms of cutting ability appears to be traded-off against a reduction in transportation speed, even when the larger fragment sizes being transported were controlled for. Old age in a wide diversity of animals has been found to be associated with reduced running speed due to effects such as neuromuscular degeneration and oxidative damage (Forster et al. 1996; Punzo and Chavez 2003; Ridgel and Ritzmann 2005), and the same may therefore be true of leaf-cutting ants.

The results emphasize that not all ants are equal. Even during foraging under controlled conditions and on a standardized material, the foraging performance of individual leaf-cutting ants varied substantially, with not only size, but also age and genotype having significant effects on foraging performance. Although the benefit of age was counterbalanced by reduced running speed, certain patrilines of ants were better foragers than others in multiple ways. Genotype can therefore affect the ability, as well as the previously shown propensity (Oldroyd and Fewell 2007; Waddington et al. 2010), to do tasks and it will be interesting to discover whether genotypes which are better at a particular task also have greater propensity to engage in it. The results provide an additional mechanism by which polyandry may improve the task performance of social insect colonies.

\section{SUPPLEMENTARY MATERIAL}

Supplementary material can be found at http://www.beheco. oxfordjournals.org/.

\section{FUNDING}

This work was supported by the Royal Society and by a Leverhulme Foundation Prize to W.O.H.H.

We thank IBAMA for permission to collect and export the ant colonies from Brazil, Crystal Frost for assistance with caring for the colonies, and Adam Smith, Wolfgang Forstmeier, and an anonymous reviewer for comments which improved the manuscript.

\section{REFERENCES}

Arathi HS, Spivak M. 2001. Influence of colony genotypic composition on the performance of hygienic behaviour in the honeybee, Apis mellifera L. Anim Behav. 62:57-66.

Armitage SAO, Boomsma JJ. 2010. The effects of age and social interactions on innate immunity in a leaf-cutting ant. J Insect Physiol. 56:780-787.

Arnqvist G, Nilsson T. 2000. The evolution of polyandry: multiple mating and female fitness in insects. Anim Behav. 60:145-164.

Camargo RS, Forti LC, Lopes JFS, Nagamoto NS. 2006. Studies on leaf-cutting ants, Acromyrmex spp. (Formicidae, Attini): behavior, reproduction and control. Recent Res Dev Entomol. 5:1-21.

Chapman NC, Oldroyd BP, Hughes WOH. 2007. Differential responses of honeybee (Apis mellifera) patrilines to changes in stimuli for the generalist tasks of nursing and foraging. Behav Ecol Sociobiol. 61:1185-1194.

Crozier RH, Fjerdingstad EJ. 2001. Polyandry in social Hymenopteradisunity in diversity? Annales Zoologici Fennici. 38:267-285.

Crozier RH, Page RE. 1985. On being the right size-male contributions and multiple mating in social Hymenoptera. Behav Ecol Sociobiol. 18:105-115. 
Evison SEF, Hughes WOH. 2011. Genetic caste polymorphism and the evolution of polyandry in Atta leaf-cutting ants. Naturwiss. 98:643-649.

Fjerdingstad EJ, Boomsma JJ, Thoren P. 1998. Multiple paternity in the leafcutter ant Atta colombica-a microsatellite DNA study. Heredity. 80:118-126.

Forster MJ, Dubey A, Dawson KM, Stutts WA, Lal H, Sohal RS. 1996. Age-related losses of cognitive function and motor skills in mice are associated with oxidative protein damage in the brain. Proc Natl Acad Sci U S A. 93:4765-4769.

Goulson D, Peat J, Stout JC, Tucker J, Darvill B, Derwent LC, Hughes WOH. 2002. Can alloethism in workers of the bumblebee, Bombus terrestris, be explained in terms of foraging efficiency? Anim Behav. 64:123-130.

Haapaniemi K, Pamilo P. 2012. Reproductive conflicts in polyandrous and polygynous ant Formica sanguinea. Mol Ecol. 21:421-430.

Helmkampf M, Gadau J, Feldhaar H. 2008. Population- and sociogenetic structure of the leaf-cutter ant Atta colombica (Formicidae, Myrmicinae). Insectes Soc. 55:434-442.

Hölldobler B, Wilson EO. 1990. The ants. Cambridge (MA): Belknap Press.

Holman L, Stürup M, Trontti K, Boomsma JJ. 2011. Random sperm use and genetic effects on worker caste fate in Atta colombica leaf-cutting ants. Mol Ecol. 20:5092-5102.

Hughes WOH, Boomsma JJ. 2004. Genetic diversity and disease resistance in leaf-cutting ant societies. Evolution. 58:1251-1260.

Hughes WOH, Boomsma JJ. 2007. Genetic polymorphism in leaf-cutting ants is phenotypically plastic. Proc R Soc Lond B. 274:1625-1630.

Hughes WOH, Boomsma JJ. 2008. Genetic royal cheats in leaf-cutting ant societies. Proc Natl Acad Sci U S A. 105:5150-5153.

Hughes WOH, Bot ANM, Boomsma JJ. 2010. Caste-specific expression of genetic variation in the size of antibiotic-producing glands of leaf-cutting ants. Proc R Soc Lond B. 277:609-615.

Hughes WOH, Oldroyd BP, Beekman M, Ratnieks FLW. 2008a. Ancestral monogamy shows kin selection is key to the evolution of eusociality. Science. 320:1213-1216.

Hughes WOH, Ratnieks FLW, Oldroyd BP. 2008b. Multiple mating or multiple queens: two routes to genetic diversity in the eusocial Hymenoptera. J Evol Biol. 21:1090-1095.

Hughes WOH, Sumner S, Van Borm S, Boomsma JJ. 2003. Worker caste polymorphism has a genetic basis in Acromyrmex leaf-cutting ants. Proc Natl Acad Sci U S A. 100:9394-9397.

Jaffé R, Kronauer DJC, Kraus FB, Boomsma JJ, Moritz RFA. 2007. Worker caste determination in the army ant Eciton burchellii. Biol Lett. 3:513-516.

Jennions MD, Petrie M. 2000. Why do females mate multiply? A review of the genetic benefits. Biol Rev. 75:21-64.

Johnson B. 2010. Division of labor in honeybees: form, function, and proximate mechanisms. Behav Ecol Sociobiol. 64:305-316.

Jones JC, Myerscough MR, Graham S, Oldroyd BP. 2004. Honey bee nest thermoregulation: diversity promotes stability. Science. 305:402-404.

Mattila HR, Seeley TD. 2007. Genetic diversity in honey bee colonies enhances productivity and fitness. Science. 317:362-364.

Milne CP. 1985. Estimates of the heritabilities of and genetic correlation between 2 components of honey bee (Hymenoptera, Apidae) hygienic behaviour-uncapping and removing. Ann Entomol Soc Am. 78:841-844

Nehring V, Evison SEF, Santorelli L, D'Ettorre P, Hughes WOH. 2011. Kin-informative recognition cues in ants. Proc R Soc Lond B. 278:1942-1948.

Norusis MJ. 2011. IBM SPSS Statistics 19 advanced statistical procedures companion. Harlow (UK): Pearson.

O'Donnell S, Jeanne RL. 1992. Forager success increases with experience in Polybia occidentalis (Hymenoptera, Vespidae). Insectes Soc. 39:451-454.

Oldroyd BP, Fewell JH. 2007. Genetic diversity promotes homeostasis in insect colonies. Treds Evol Ecol. 22:408-413.
Oldroyd BP, Sylvester HA, Wongsiri S, Rinderer TE. 1994. Task specialization in a wild bee, Apis florea (Hymenoptera, Apidae), revealed by RFLP banding. Behav Ecol Sociobiol. 34:25-30.

Ortius-Lechner D, Gertsch PJ, Boomsma JJ. 2000. Variable microsatellite loci for the leaf cutter ant Acromyrmex echinatior and their applicability to related species. Mol Ecol. 9:114-116.

Pankiw T, Page RE. 2001. Genotype and colony environment affect honeybee (Apis mellifera L.) development and foraging behavior. Behav Ecol Sociobiol. 51:87-94.

Peat J, Goulson D. 2005. Effects of experience and weather on foraging rate and pollen versus nectar collection in the bumblebee, Bombus terrestris. Behav Ecol Sociobiol. 58:152-156.

Punzo F, Chavez S. 2003. Effect of aging on spatial learning and running speed in the shrew (Cryptotis parva). J Mammal. 84:1112-1120.

Ravary F, Lecoutey E, Kaminski G, Chaline N, Jaisson P. 2007. Individual experience alone can generate lasting division of labor in ants. Curr Biol. 17:1308-1312.

Reichardt AK, Wheeler DE. 1996. Multiple mating in the ant Acromyrmex versicolor: a case of female control. Behav Ecol Sociobiol. $38: 219-225$

Rheindt FE, Strehl CP, Gadau J. 2005. A genetic component in the determination of worker polymorphism in the Florida harvester ant Pogonomyrmex badius. Insectes Soc. 52:163-168.

Ridgel AL, Ritzmann RE. 2005. Insights into age-related locomotor declines from studies of insects. Ageing Res Rev. 4:23-39.

Robinson GE. 1992. Regulation of division of labor in insect societies. Annu Rev Entomol. 37:637-665.

Robinson GE. 2009. Physiology as a caste-defining feature. Insectes Soc. 56:1-6.

Robinson GE, Page RE. 1988. Genetic determination of guarding and undertaking in honeybee colonies. Nature. 333:356-358.

Roces F, Nunez JA. 1993. Information about food quality influences load-size selection in recruited leaf-cutting ants. Anim Behav. 45:135-143.

Roschard J, Roces F. 2003. Fragment-size determination and size-matching in the grass-cutting ant Atta vollenweideri depend on the distance from the nest. J Trop Ecol. 19:647-653.

Rudolph SG, Loudon C. 1986. Load size selection by foraging leaf-cutter ants (Atta cephalotes). Ecol Entomol. 11:401-410.

Schippers MP, Dukas R, Smith RW, Wang J, Smolen K, McClelland GB. 2006. Lifetime performance in foraging honeybees: behaviour and physiology. J Exp Biol. 209:3828-3836.

Schofield R, Emmett K, Niedbala J, Nesson M. 2011. Leaf-cutter ants with worn mandibles cut half as fast, spend twice the energy, and tend to carry instead of cut. Behav Ecol Sociobiol. 65:969-982.

Simmons LW. 2005. The evolution of polyandry: sperm competition, sperm selection, and offspring viability. Annu Rev Ecol Evol Syst. $36: 125-146$.

Smith CR, Anderson KE, Tillberg CV, Gadau J, Suarez AV. 2008. Caste determination in a polymorphic social insect: nutritional, social, and genetic factors. Am Nat. 172:497-507.

Sumner S, Hughes WOH, Pedersen JS, Boomsma JJ. 2004. Ant parasite queens revert to mating singly. Nature. 428:35-36.

Waddington SJ, Hughes WOH. 2010. Waste management in the leaf-cutting ant Acromyrmex echinatior: the role of worker size, age and plasticity. Behav Ecol Sociobiol. 64:1219-1228.

Waddington SJ, Santorelli LA, O'Ryan FR, Hughes WOH. 2010. Genetic polyethism in leaf-cutting ants. Behav Ecol. 21:1165-1169.

Weber NA. 1972. Gardening ants: the attines. Mem Am Phil Soc. 92:1-146.

Willott SJ, Compton SG, Incoll LD. 2000. Foraging, food selection and worker size in the seed harvesting ant Messor bouvieri. Oecologia. 125:35-44.

Wilson EO. 1980. Caste and division of labor in leaf-cutter ants (Hymenoptera, Formicidae, Atta). 2. The ergonomic optimization of leaf cutting. Behav Ecol Sociobiol. 7:157-165. 